\title{
Evaluation of a data-based hydrological model for simulating the runoff of medium sized Andean basins
}

\author{
Rolando Célleri $^{{ }^{*}}$, Patrick Willems ${ }^{2}$, Jan Feyen ${ }^{1}$ \\ ${ }^{1}$ Grupo de Ciencias de la Tierra y del Ambiente, Dirección de Investigación, Universidad de Cuenca, \\ Av. 12 de Abril s/n, Cuenca, Ecuador \\ ${ }^{2}$ Hydraulics Laboratory, Faculty of Engineering, Katholieke Universiteit Leuven, Leuven, Belgium \\ *E-mail: rcelleri@gmail.com
}

Fecha de recepción: 7 de octubre 2010 - Fecha de aceptación: 8 de noviembre 2010

\section{RESUMEN}

El modelo conceptual agregado VHM, basado en una técnica de minería de datos y capaz de adaptar su estructura a distintos grados de complejidad usando entre 5 y 15 parámetros, fue implementado en dos cuencas andinas del Sur del Ecuador de 300 y $1260 \mathrm{~km}^{2}$ usando series de tiempo de lluvia y caudal. Este artículo detalla el procedimiento seguido para identificar la estructura del modelo, realizar su calibración y validación, así como el enfoque multi-objetivo utilizado para evaluar el desempeño del modelo y sus componentes. Para incrementar la información existente en las series de caudal, éstas fueron divididas en series de tiempo de subflujos de caudales rápidos, intermedios y base, y las nuevas series fueron discretizadas en eventos independientes de caudales altos y bajos. Se encontró que la estructura del modelo compuesta solamente por un módulo para almacenamiento de agua en el suelo, flujos rápidos y flujos lentos fue capaz de modelar el balance agua y los caudales de las dos cuencas con una precisión aceptable. Se identificó que un valor bajo de la capacidad de almacenamiento del suelo facilita la calibración del modelo (identificación de sus parámetros) pero no da una garantía para mejorar el desempeño del modelo. El estudio reveló también que las estructuras más simples del modelo reducen fuertemente el riesgo de sobre parametrización del modelo y su incertidumbre asociada.

Palabras clave: Minería de datos, modelo hidrológico basado en datos, calibración, validación, evaluación multi-objetivo, análisis secuencial.

\begin{abstract}
Using timeseries of rainfall and streamflow of two basins in the Andean mountain range, South Ecuador, different in size (300 and $1260 \mathrm{Km}^{2}$ ), a generalized lumped conceptual model (VHM), offering the possibility of using different levels of complexity with number of model parameters varying between 5 and 15, was tested. To increase the information timeseries of total streamflow were split in timeseries of quick, intermittent and baseflow, and the timeseries were discretized to select independent events of high and low flows. The paper outlines in detailed the procedure for the model structure identification, calibration and validation, as well as the multi-objective criteria approach used to evaluate the performance of the model and its components. It has been shown that the model structure, consisting of a module for soil storage and quick flow, was able to model for both basins the water balance and streamflow components with acceptable accuracy. A low value of the soil water storage facilitates the model calibration but it is not a guarantee that the model performs better. The study further reveals that the risk of over-parameterization and associated uncertainty reduces strongly the more simple the structure of the model.
\end{abstract}

Keywords: Data-mining, data-based hydrological model, split-sample, streamflow components, calibration, validation, multi-objective evaluation, step-wise analysis. 


\section{INTRODUCTION}

One problem that hinders the study of the hydrology of mountain areas is the lack of proven models. A large variety of model conceptualizations exist (Singh, 1995; Singh and Frevert, 2002a,b), from simple lumped conceptual to physically-based, semi- or fully-distributed models. Traditionally lumped models aggregate or lump the catchments' climate, soils, topography and vegetation into a single unit (e.g., the HEC-1, NAM and HBV models). A variation is the application of a conceptual representation of the hydrological cycle at the main elevation bands or at subbasin level, routing the outflow of each elevation band or subbasin to the next lower laying elevation band or subbasin (e.g., Eder et al., 2005). Well known examples of distributed models are the TOPMODEL, SWAT, MIKE SHE. Identification which rainfall-runoff model is most suited for a given basin is rather complex and to a certain extent controlled by the objective of the model application (e.g., estimation of the temporal and spatial variation in water resources, flood forecast, assessment of land-use effects, real-time operation of hydraulic structures, among others), and the input requirements versus data availability.

While the use of complex modeling tools may look appealing for the unraveling of the rainfallrunoff process, the lack of adequate hydro-meteorological, soil and land cover data and the large spatial and temporal variability in mountainous regions, such as the Andean mountain range, strongly hampers the use of detailed models. The main problem of these models, according to Burlando et al. (2002), is the sub-grid parameterization. Sub-grid parameterization in mountain areas is not that evident due to the strong gradients in topography, land use and physical properties. When the grid-size is chosen small enough to reduce sub-grid parameterization problems, over-parameterization occurs, i.e., there are just too many model parameters so that a good agreement between observed and simulated runoff can always be achieved. Although model structure uncertainties might decrease with increasing model detail, its effect is likely overcompensated by input and parameter uncertainties. In the case of Andean catchments, data is so scarce that when using a distributed, physically-based model, input and parameter uncertainties will be high and most likely the model will not be parsimonious but non-behavioral. This means that different model structures and sets of parameter values will give similar model performance, a problem that Beven and Binley (1992) termed equifinality. The problem of equifinality is not only typical for detailed models, as explained in the following.

Let's consider the case of lumped-conceptual models. The simplest schematization of a basin is a reservoir ("bucket") (Manabe, 1969; referred to by Atkinson et al., 2002). Discharge is produced by saturation excess when the reservoir is full, and subsurface delayed flow can be presented as a linear function of storage when the storage exceeds a given threshold. The reservoir representation could be expanded by introducing a baseflow mechanism (e.g., a linear function of storage, independent of its state). Additionally, discharge can also be simulated by infiltration excess (e.g., as a linear function of soil infiltration capacity and rainfall intensity). Furthermore, model detail can be added by including a deep groundwater reservoir, again as a linear function of storage. Most of these processes can be transformed to non-linear functions. The resulting model can easily have more than 15 parameters to be calibrated, and this figure can increase even more should snow-melting processes have to be included.

Calibration of a model code of this complexity, applied in a basin with limited data, easily results to an over-tuning of the parameters. This has been shown by Aizen et al. (2000) who applied a singleand a two-reservoir model in alpine regions of Central Asia. Their study clearly showed that the tworeservoir model yielded minor improvements at the expense of higher uncertainty in model structure. Kokkonen and Jakeman (2001) probably carried out the most comprehensive analysis of this type by applying two models with different levels of conceptualization to a number of catchments. Their results suggest that the model with simpler model structure provides, in general, a more accurate reproduction of streamflow, and they concluded that when only rainfall-runoff data are available, it is difficult to justify the inclusion of additional processes in the model structure. In other words, for datalimited catchments models can be excessively detailed or according to Young (2003) "models have a surplus (mathematical) content not supported by the available data". 
To overcome the problem over parameterization, data-based mechanistic (DBM) models have been developed (Young, 2003). DBM hydrological models use data-mining techniques which strive to "the nontrivial extraction of implicit, previously unknown, and potentially useful information" (Frawley et al., 1992). The objective is to convert a set of observations into a model scheme that provides a better understanding of the hydrological processes than the observations (Babovic, 2005). Data-mining helps to identify the model structure and the testing of hypotheses about the structure. Parameters can be estimated independently or derived via model calibration. It is the observations that drive the complexity needed in the model, avoiding any preconceived notion of the behavioral mechanics of the system. Applications of this type of models in lowland catchments are reported by Jakeman et al. (1990), Young (2001 and 2003) and references therein. IHACRES (Littlewood et al., 1997) and HYCOM (Lees et al., 1998) are examples of DBM models. Applications of DBM models are widely reported in literature, e.g., Post and Jakeman (1996); Sefton and Howarth (1999); Lees (2000); Schreider et al. (2001); Limbrick (2002); Croke et al. (2006). By lack of detailed bio-physical data, the complex topographic conditions and the large rainfall variability DBM models are probably promising for the analysis of Andean basins (Célleri et al., 2007).

The purpose of this study is to use the data-mining approach of Willems (2000), linked to a modular lumped-conceptual hydrological model, to analyze the hydrology of medium sized Andean river basins (300-1260 $\left.\mathrm{Km}^{2}\right)$ in South Ecuador. Verification of the applicability of the approach was pursued by conducting a detailed performance assessment (Célleri, 2007).

\section{MATERIALS AND METHODS}

\subsection{The data-mining approach and lumped-conceptual model}

The VHM approach of Willems (2000) (where VHM stands for "generalized lumped conceptual modeling") used in this study uses the DBM modeling principles and has been successfully applied to several basins. However, even for DBM hydrological models the difficulty of transforming daily rainfall into runoff persists due to the heterogeneity of catchment physical features and the spatial variability of rainfall. To overcome this problem, Klemes (1983) suggested an approach called "downward approach to hydrologic modeling" based on the analysis of hydrological data at different time scales of aggregation. The rationale behind this approach is that knowledge about the hydrological functioning of a catchment can be derived by analyzing timeseries at different time scales, i.e., daily, weekly, monthly and annual, and that models of acceptable accuracy for the intended purpose can be extracted from this information. Unfortunately, as stated by Klemes (1983) the hydrological response of basins not necessarily is the same for each of the time scales.

Another scale, not often explored for the understanding of the hydrology of a catchment is the event scale, which likely better expresses the time variability of climate and basin characteristics. The VHM approach is based on the analysis of the timeseries of independent hydrological events, which enables the analysis of particular processes, such as quick flow (peak event) and baseflow (recession event). The VHM approach is a good example of a data-mining technique, applied to well defined periods of timeseries of hydrological data. The main features of the approach are described in the following. For a complete description the reader is referred to Willems (2000).

1. The core concept of the VHM approach is the extraction of information from timeseries of observed discharge representing the hydrological signature of a given catchment, and using this information for constructing a robust, parsimonious hydrological model. The most important physically-based information present in discharge series are: (i) the characteristics of hydrological events, and (ii) the components of total flow, i.e., baseflow, interflow and quick flow.

2. The approach assumes that rainfall in a time-variant way is distributed into 3 sub-flows (see Figure 1a). Thus, part of the rainfall contributes to quick flow (QF), interflow (IF), and baseflow $(\mathrm{BF})$; the rest is stored as soil moisture or lost by evapotranspiration (ET). 
3. The hydrological model tied to the VHM approach uses a general conceptual model structure (Figure 1b) with storage elements representing the surface, unsaturated zone and groundwater storages. These storages are combined with reservoir models to describe the routing of the subflows. The model structure is not fixed, and it has to be identified for each specific case. Therefore it consists of several independent modules representing the different processes that may be present in the catchment. The basic module is the soil storage module which, depending on the dynamics of soil hydrology, can take different mathematical forms (e.g., linear or exponential) to relate the storage fraction of precipitation and the soil moisture state. In addition, there are modules for simulating IF and QF (although IF and QF combined can be analyzed) by both infiltration and saturation excess mechanisms. The simplest model structure has 7 parameters and the most complex 18, although more complex structures can be implemented.

(a)

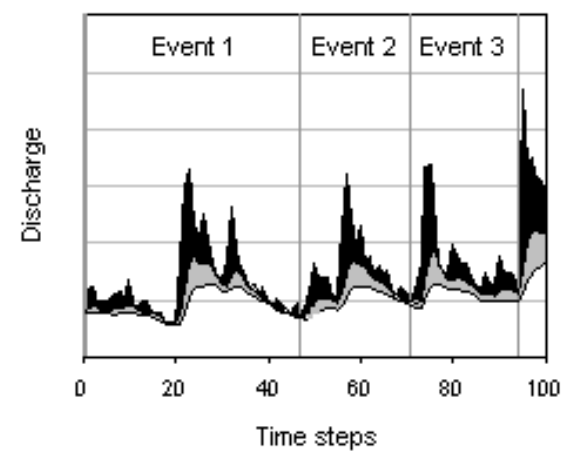

\begin{tabular}{|c|c|c|c|c|}
\cline { 2 - 5 } \multicolumn{1}{c|}{} & \multicolumn{4}{c|}{ Events } \\
\cline { 2 - 5 } \multicolumn{1}{c|}{} & 1 & 2 & $\ldots$. & $\mathrm{n}$ \\
\hline $\mathrm{QF} / \mathrm{P}$ & $\mathrm{fq} 1$ & $\mathrm{fq} 2$ & $\ldots$. & $\mathrm{fqn}$ \\
\hline $\mathrm{IF} / \mathrm{P}$ & $\mathrm{fi} 1$ & $\mathrm{fi} 2$ & $\ldots$. & $\mathrm{fin}$ \\
\hline $\mathrm{BF} / \mathrm{P}$ & $\mathrm{fb} 1$ & $\mathrm{fb} 2$ & $\ldots$. & $\mathrm{fbn}$ \\
\hline
\end{tabular}

QF: quick flow

IF: interflow

BF: baseflow

$\mathrm{P}$ : precipitation fq: $Q F$ fraction of rainfall

fi: IF fraction of rainfall

$\mathrm{fb}$ : $\mathrm{BF}$ fraction of rainfall

fu: storage fraction or rainfall

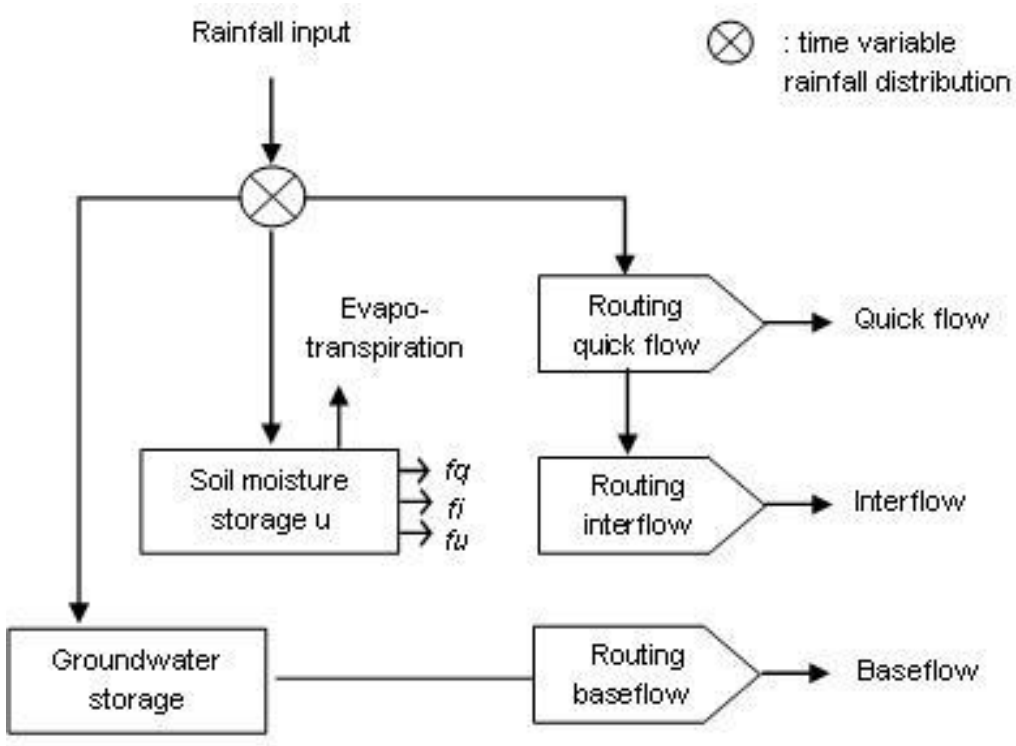

(b)

Figure 1. (a) Scheme of the VHM concept: discharge separation into sub-flows and independent events, and the subsequent calculation of precipitation fractions; (b) General lumped conceptual rainfall-runoff model structure (simplified from Willems, 2000).

4. Modules are calibrated by trial-and-error in a step-wise way starting from the soil storage module which controls BF and ET, followed by the OF and IF modules. The separate calibration of each module to the different observed sub-flows makes the calibration transparent. The main advantage of the approach is that the effect of each module on the simulation model is observable and comparable to the observed data. Modules that are not supported by the observations are excluded from the model. In this way the model structure is derived in a case-specific, optimal way and its identification becomes part of the calibration 
process. The approach allows calibration of parameters per module minimizing the risk of over parameterization and reducing the total calibration time.

5. The performance of the data-based sub-models is evaluated by multi-objective criteria as detailed in Section 3.1.

\subsection{Model calibration, validation and performance evaluation}

Model calibration is the process by which a model code is set-up for a specific basin by adjusting all or some (most sensitive) model parameters. This is done by assessing the model performance (i.e., the level of agreement between model output and observations) using statistical parameters. To test the model performance, the calibration process is usually followed by a validation of the model to data not used for calibration (Klemes, 1986; Refsgaard and Knudsen, 1996). To this end timeseries of hydrological data are split into two, a series for model calibration and a series for model validation. During the validation no fine-tuning of parameters is pursued. When the calibrated model underperforms in the validation this might mean that the model was poorly calibrated or that the two timeseries are strongly different in rainfall-runoff response as a consequence of either a change in climate or a drastic change in catchment properties (e.g., reforestation) prohibiting the calibrated model to properly capture the runoff process during the timeseries used for model validation.

In addition to the traditional statistical analyses between simulated and observed discharges [e.g., the mean square error (MSE) and the coefficient of efficiency (EF) (Nash and Sutcliffe, 1970)] in this study the properties of the flow timeseries are also analyzed using goodness-of-fit plots (Willems, 2005). The rationale behind this is that a graphical comparison of the modeled versus observed discharges provides complementary information to the used statistical criteria. This for example allows identifying that a model with low EF might perform well except for a few outliers in the timeseries. Additionally, the graphical comparison might provide information on the weak points in the model (e.g., simulated poorly low or high flows). Willems (2000 and 2005) proposed the following graphical evaluation in addition to the statistical performance assessment:

1. Graphical comparison of Box-Cox transformed observed and simulated quick and slow flows using scatter plot. A Box-Cox transformation (Box and Cox, 1964) is applied to suppress the variance on the flow magnitudes, because model residuals (or model errors) tend to increase with the magnitude of the flow values. EF and other statistics give more weight to the higher flow values and therefore a calibration after transformation assures that equal weight is given to all flow magnitudes.

2. Comparison of the observed and simulated cumulative volumes of total flow, BF, IF and QF.

3. Extreme value analysis of observed and simulated high and low flows using the extreme value distribution plot.

4. Visual comparison of timeseries of observed and simulated flows, flow duration curves of observed and simulated total, quick and slow flow values, and design of scatter plots of daily observed and simulated flow components.

\subsection{Step-wise methodology}

The methodology for model calibration and validation, used in this study, follows a step-wise approach and is described in the following.

1. The first step consists in the separation (filtering) of sub-flows from the series of total discharge. Hereto the WETSPRO (Water Engineering Time Series PROcessing tool) software package (Willems, 2000 and 2004) is used. The package uses a digital numerical filtering technique (Chapman, 1991) to separation total flow in its components. The method is based on the linear reservoir concept and the exponential recession of sub-flows and the similitude between electronic signals (higher and lower frequency signals) and discharge composition (higher and lower recession constants). The filter can also be used to separate timeseries of measurements consisting of the accumulation of exponentially recessive components (as is the case for streamflows) into its components, each of them characterized by its recession coefficient. 
Baseflow is first separated from the total discharge; then interflow from the remaining discharge (i.e., the total streamflow minus baseflow).

2. Then the timeseries are split into nearly independent hydrological events using the Peak-OverThreshold (POT) method (see WETSPRO). Two types of events are identified: quick flow events (for independent quick flow peaks) and slow flow events (for independent baseflow periods). The criteria for the selection of POT values are: (i) the inter-event time exceeds the recession constant for the considered sub-flow; and (ii) the minimum inter-event discharge drops close to the baseflow value (i.e., when quick flow is negligible compared to baseflow). When these criteria are met subsequent independent events can be selected, and the event maximum is selected as the maximum discharge during the event. In a similar manner, using the recession constant for baseflow, nearly independent slow flow periods can be identified and baseflow minima selected as the minimum discharge during the event.

3. Timeseries of discharge, precipitation, ET, sub-flows and POT values for peak and low flows are fed into the VHM model. For every event the sub-flows and precipitation volumes are aggregated and the fraction precipitation/sub-flow calculated.

4. Model structure identification and calibration starts by identifying the mathematical description of the Soil Storage Module (SSM). This is done by analyzing the scatter plot of the fraction of precipitation that remains in storage versus the soil moisture state for all events. The scatter of the data points indicates the mathematical function to be used. Normally, the SSM has a linear or exponential shape but any other mathematical function can be used. Once the function is chosen, the calibration of the module starts. This module has 5 or 6 parameters for the linear and exponential cases, respectively. In this study the expected range of the $u_{\max }$ parameter (maximum soil water content) is derived using the following equation:

$$
u_{\max }=p * D
$$

where $p$ is the mean soil porosity and $D$ the mean soil depth.

Mean porosity is calculated as the weighted mean of the soil porosities calculated for the different sub-areas in which the basin is divided. For the calculation of mean soil depth a slope map is derived from a 50-m digital elevation model. Slopes are then classified into 6 ranges, and a soil depth assigned to each range. Mean soil depth is calculated as the weighted mean of soil depths. Upper and lower limits of $u_{\max }$ are defined by analyzing a number of variations in soil depth and porosity. Parameter $u_{\text {init }}$ refers to the initial wetness condition of the basin and is only important in the warm-up period of the model. This leaves only 4 or 5 parameters to be calibrated. Model calibration is straightforward, thanks to the visual tools in WETSPRO. Module performance is evaluated by plotting the modeled and observed volumes of baseflow (after Box-Cox transformation with $\mathrm{BC}(\mathrm{Q})=\left(\mathrm{Q}^{\lambda}-1\right) \lambda^{-1}$ and $\left.\lambda=0,25\right)$ for every nearly independent slow flow event and using the statistics Standard Deviation and Mean Squared Error.

5. The second module to be calibrated is the Quick Flow Module (QFM). This is carried out by analyzing the scatter plot of the fraction of precipitation that goes to Quick Flow versus the soil moisture state for all events, and tuning 2 parameters that describe the saturation excess mechanism and/or 2 parameters that describe the infiltration excess mechanism. Therefore the least complex module has 2 parameters and the most complex 4 parameters. As for the calibration of the baseflow module, the visual tools facilitate the calibration process of the quick flow module. Performance is evaluated by plotting the modeled and observed volumes of quick flow (after Box-Cox transformation with $\lambda=0,25$ ) for every nearly independent quick flow event and using the statistics Standard Deviation and Mean Squared Error.

6. In the $6^{\text {th }}$ step of the procedure, the Interflow Module is calibrated. This is done in a similar way as explained in the Steps 4 and 5. 
7. Once all modules are calibrated one can proceed to simulate the basin discharge. For the routing the model needs the recession constants of each sub-flow. These are the values determined in Step 1, and therefore not subject to calibration. Model performance is evaluated using the criteria described in Section 2.2. Since every module has been optimally calibrated, the final model, in theory, needs no calibration.

8. The sub-modules are validated using the timeseries of input data not used for calibration, following the procedure outlined in previous steps.

9. Steps 5 till 8 are repeated increasing model complexity until the model performance no longer improves. Table 1 shows the module combinations that can be tested for any basin.

\subsection{Sensitivity analysis}

Simulation output is affected by two types of uncertainties: (i) hydrological model parameters; and (ii) criteria used for selecting independent events. Only the sensitivity to model parameters was performed, using the following scheme: once the model is calibrated parameters are changed (increased and decreased) and the model is run. The change in model performance reflects the sensitivity for the model parameters. In fact the sensitivity analysis was limited in assessing the simulation results with respect to the value of the $u_{\max }$ parameter (maximum soil water storage). High $u_{\max }$ values imply a large storage capacity of the basin which can be the product of deep soils or soils with high retention capacity. This translates to lower relative soil moisture values, lower peak discharges and high baseflows. Conversely, low $u_{\max }$ values allow the soil to saturate quickly, producing therefore high peaks; however after a rainless period soils dry out quickly as well. On the other hand, since calibration of model parameters for the SM, QF and IF modules is a matter of adjusting a linear or exponential model to the observations, the sensitivity analysis for these modules was based on calculating the confidence intervals for every module in the model and analyzing module structure effects within the confidence intervals.

\subsection{Study basins and data availability}

Two sub-basins of the Paute Basin were selected, the Matadero $\left(300 \mathrm{Km}^{2}\right)$ and Tomebamba $(1260$ $\mathrm{Km}^{2}$ ) basins, respectively. The basins are located on the southern Ecuadorian Andes, in the InterAndean Depression that separates the Real (Eastern) and Western Cordilleras of the Andes. The basins are equipped by a relative dense network of rain gauges (on average $1 / 150 \mathrm{Km}^{2}$ ) and limnigraphic stations, since they host the Paute Hydropower Plant, producing over 50\% of Ecuador's electrical energy. Unfortunately the distribution of rain gauges is highly heterogeneous and the basin presents both well covered and largely un-sampled regions. Additionally, the distribution of stations along the elevation gradient shows deficiencies as well.

Timeseries of daily precipitation are available for the period 1975-1989. Areal precipitation was calculated using the inverse distance square (IDS) technique (Tabios and Salas, 1985). While discharge and precipitation data were available for the same time span, evapotranspiration (ET) data was not. In fact, meteorological stations are scarce. In this study daily timeseries of ET were derived from mean monthly estimates. Mean monthly ET estimates were extracted for each basin from mean monthly maps generated for a regional study (Tote and De Bièvre, 2005; Bacuilima et al., 1999). Then, monthly estimates were uniformly distributed over the month.

\section{RESULTS AND DISCUSSION}

\subsection{Application of VHM model}

A detailed application of the modeling approach is described for the Tomebamba basin, set-up 3 (Table 1). Figure 2 shows the pre-processing of data previous to the hydrological modeling, i.e., the separation of sub-flows (only the filtered baseflow is shown) and the selection of nearly independent hydrological events (black dots are the POT values of quick flow events and the vertical lines separate 
slow flow periods). As can be noticed some baseflow values appear to have higher magnitudes than the total flow. This is caused by the sub-flow filtering module, which can produce positive and negative errors.

Table 1. Model structure set-up (SSM: Soil storage module; QFM: Quick flow module; IFM: Interflow module; SE: Saturation excess; IE: Infiltration excess).

\begin{tabular}{cccccc}
\hline $\begin{array}{c}\text { Model } \\
\text { Set-up }\end{array}$ & SSM & QFM $_{\mathrm{SE}}$ & QFM $_{\mathrm{IE}}$ & IFM $_{\mathrm{SE}}$ & IFM $_{\mathrm{IE}}$ \\
\hline 1 & $\checkmark$ & $\checkmark$ & & & \\
\hline 2 & $\checkmark$ & $\checkmark$ & $\checkmark$ & & \\
\hline 3 & $\checkmark$ & $\checkmark$ & & $\checkmark$ & \\
\hline 4 & $\checkmark$ & $\checkmark$ & $\checkmark$ & $\checkmark$ & \\
\hline 5 & $\checkmark$ & $\checkmark$ & & $\checkmark$ & $\checkmark$ \\
\hline 6 & $\checkmark$ & $\checkmark$ & $\checkmark$ & $\checkmark$ & $\checkmark$ \\
\hline
\end{tabular}

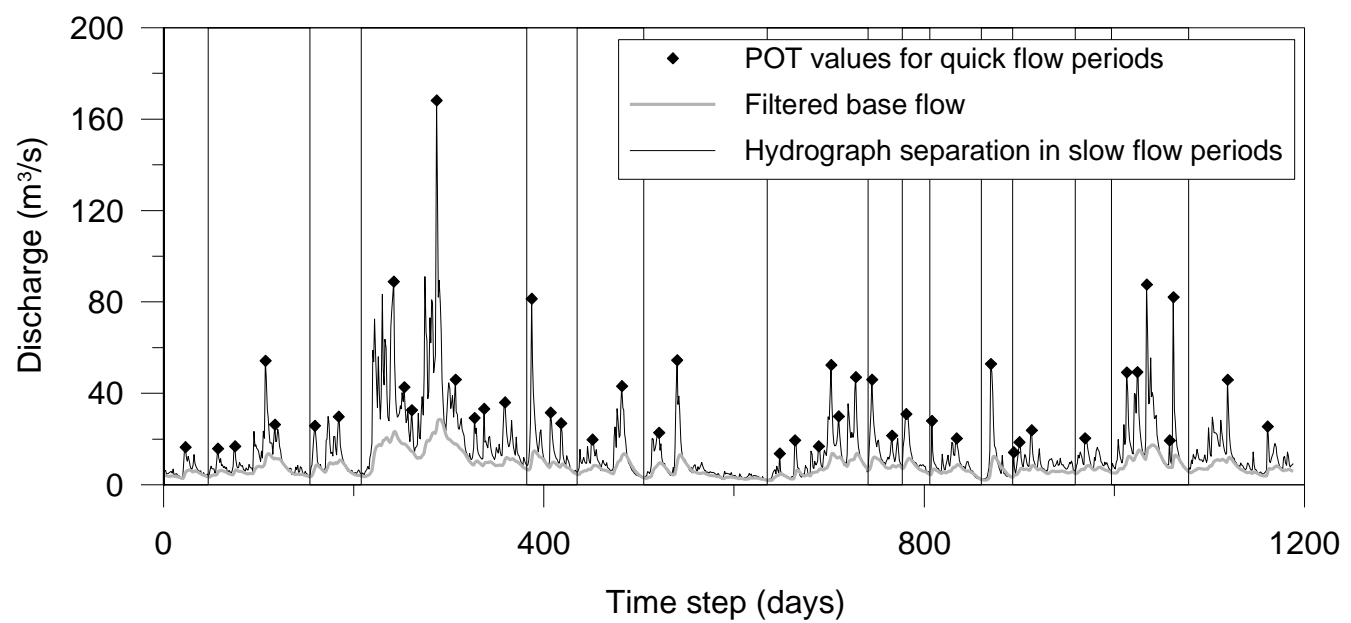

Figure 2. Baseflow and nearly independent hydrological events for the Tomebamba basin.

Figure 3 shows the calibration of the soil storage module (SSM). The soil moisture storage capacity $\left(u_{\max }\right)$ is an input parameter that cannot be determined as part of the data-mining technique. In this study $u_{\max }$ was determined by relating terrain slope (based on a $50-\mathrm{m}$ grid size DEM) to soil properties (depth and porosity) and once the most realistic value is selected; the value was kept constant in the calibration. The soil water content at maximum evapotranspiration $\left(u_{\text {evap }}\right)$ was set equal to $u_{\max }$ and not subject to calibration either. $u_{\text {init }}$ (initial water content) was fine-tuned as part of the calibration. Recession constants for the routing of discharges were determined from the analysis of recession curves and were kept constant during model calibration. In Figure 3a each point represents a nearly independent high-flow event. As can be seen, the scatter suggests that a linear equation relating the soil moisture state and the fraction of rainfall that remains stored in the basin is the best mathematical choice since more complex equations (e.g., exponential) would not improve results. The large scatter seen in the figure is mainly caused by an accumulation of input uncertainties (i.e., uncertainty in basin rainfall) and measurement errors (i.e., errors in rating curve extrapolation) given that the event storage is calculated as a residual (or rest) term of the water balance, although other variables may intervene as well such as variations in response between seasons. The calibration of the SSM reduces to the trial and error fitting of a 2-parameter model to the observed events. The validation plot of Figure $3 \mathrm{~b}$ is used to assess the procedure by comparing filtered versus modeled slow flows. A good calibration is reached when this plot shows no systematic over or underestimation of all events, as depicted in Figure 3b. Additionally the mean squared error is used as a quantitative measure 
of the goodness-of-fit. Once this module is calibrated, different model structures using combinations of quick flow and interflow modules (QFM and IFM respectively) and combination of mechanisms of runoff formation are analyzed as described in Table 1 . Hereafter follows the description for the calibration according to set-up 3. Figures 4 and 5 show the calibration plots for QFM and IFM, respectively. Similar to the SSM, the data help deriving the model parameters, constraining in this way the parameter uncertainty, and the calibration reduces to a sort of line-fitting procedure. Especially for the case of the IFM (Figure 5a), the scatter is very limited and the model can be easily derived. In the validation plots of Figures $4 b$ and $5 b$ it is important to notice that the variance remains constant for all flow conditions and that there is only a little bit of underestimation for a small number of events in the middle range of volumes.
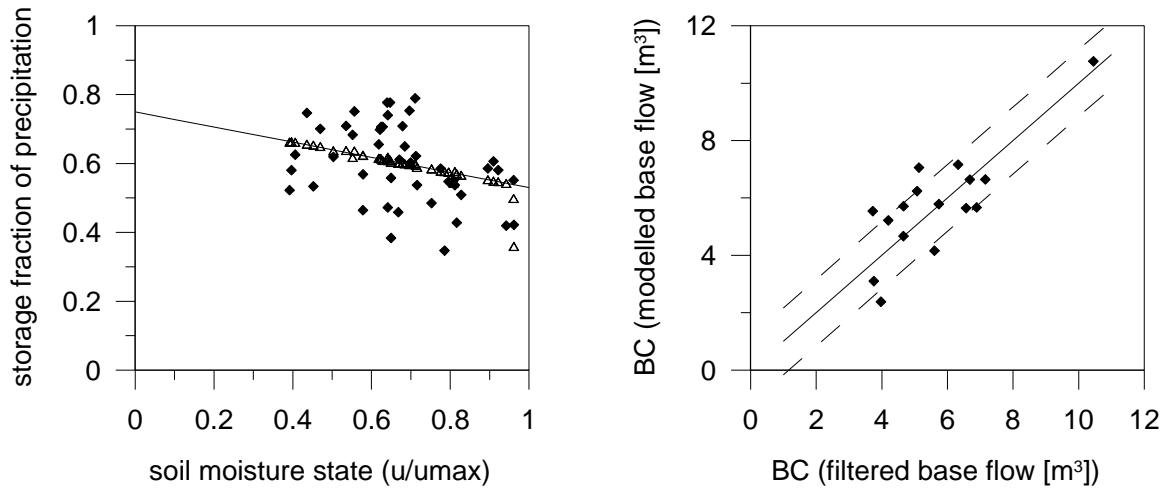

Figure 3. Soil storage module plots: (a) calibration (dots are filtered event discharges, triangles are modeled events and line is the model); and (b) performance evaluation (continuous line is the bisector; dashed lines are \pm 1 standard deviation), with application to the Tomebamba basin.
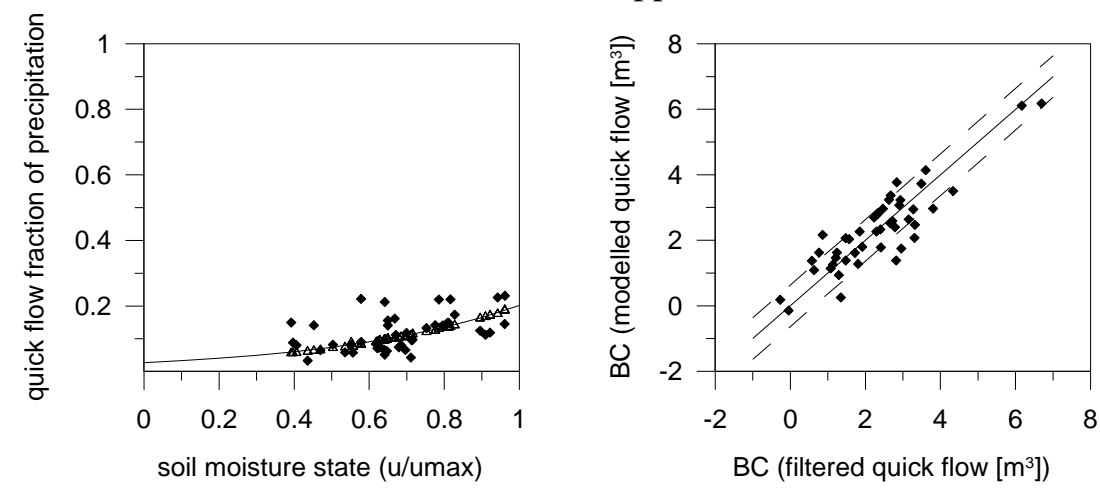

Figure 4. Quick flow module plots: (a) calibration (dots are filtered event discharges, triangles are modeled events and line is the model); and (b) performance evaluation (continuous line is the bisector; dashed lines are \pm 1 standard deviation), with application to the Tomebamba basin.

The EF coefficient of the simulation results presented in Figure 6 is 0,70 . The water balance is well simulated as depicted in Figure 7, with a total water balance error of 2,9\%. The quality of the simulation results are further analyzed plotting the flow duration curve and the scatter plot between observed and modeled flows (Figure 8). Both plots show a little overestimation of daily flows especially in the middle range of discharges. Volumes of quick flow events are, in general, well simulated (Figure 9a) with only a few events underestimated. On the other hand, slow flow event volumes are well simulated (Figure 9b). The analysis of extreme high discharges (Figure 10a) reveals that the model is underestimating high flows; something also reflected in Figures 6 and 8b, respectively the timeseries of observed and simulated streamflow and the scatter plot of daily discharge. Extreme low discharges are very well simulated as depicted in Figure 10b. 

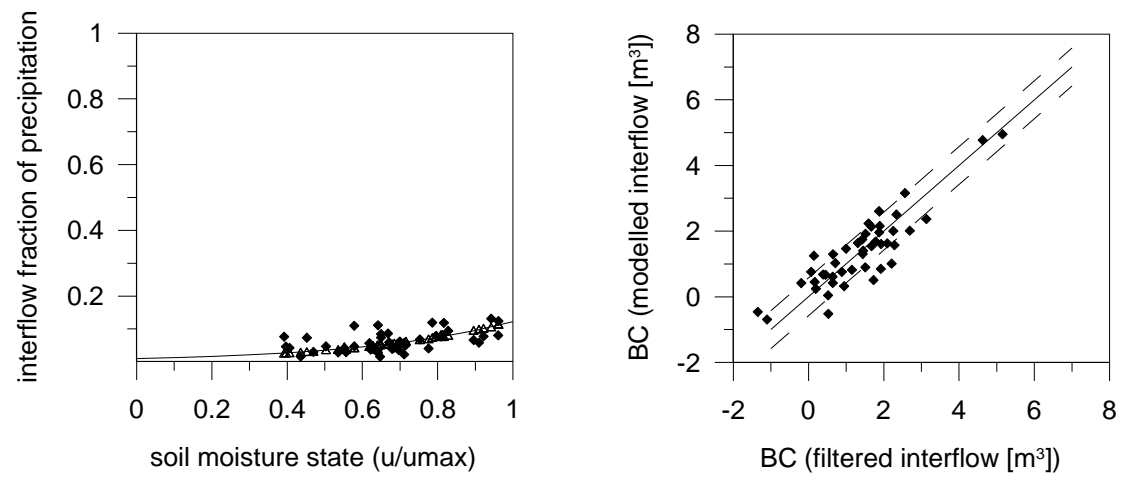

Figure 5. Interflow module plots for the Tomebamba basin: (a) calibration (dots are filtered event discharges, triangles are modeled events and line is the model); and (b) performance evaluation (continuous line is the bisector; dashed lines are \pm 1 standard deviation).

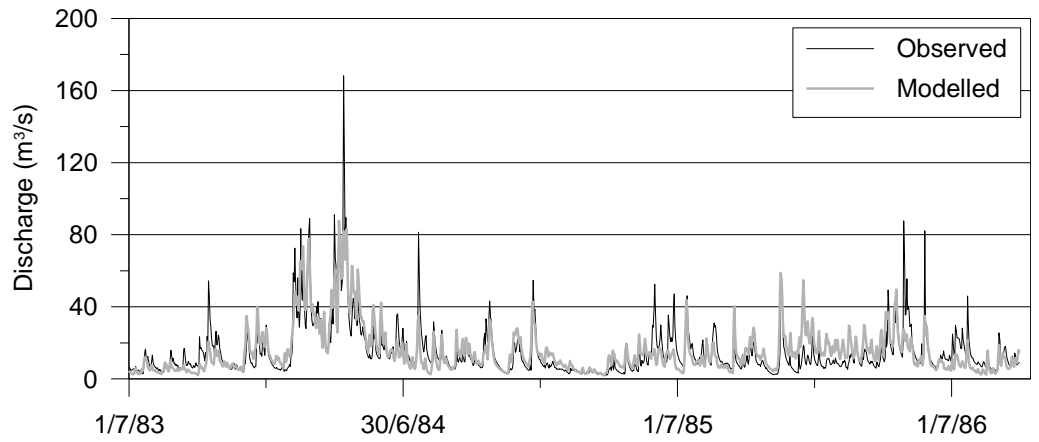

Figure 6. Timeseries of observed and simulated streamflow during model calibration, with application to the Tomebamba basin.

The complexity added in set-up 4, with respect to set-up 3, did improve simulation results only marginally. It is some calibration objectives improved slightly (e.g., better reproduction of extreme discharges) at the expense of other objectives (e.g., poorer prediction of extreme baseflows). Moreover, the simplest model structure (set-up 1) gave a similar water balance closure, and a NashSutcliffe coefficient of 0,70 , but the distribution of high flows was less satisfactory. Our study revealed that set-up 3 performs best. In the validation period (Figure 11) the water balance error was equal to $-0,5 \%$ and the coefficient of efficiency 0,64 . These results are quite satisfactory considering the quantity and quality of the data and the scale of application.

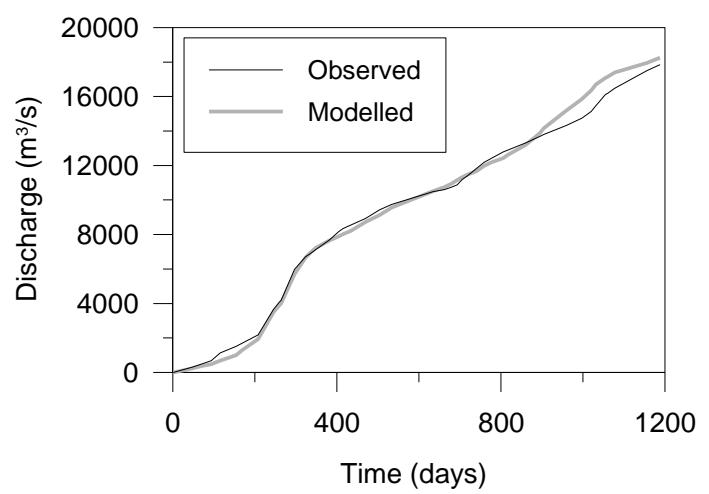

Figure 7. Water balance evaluation of the Tomebamba basin. 


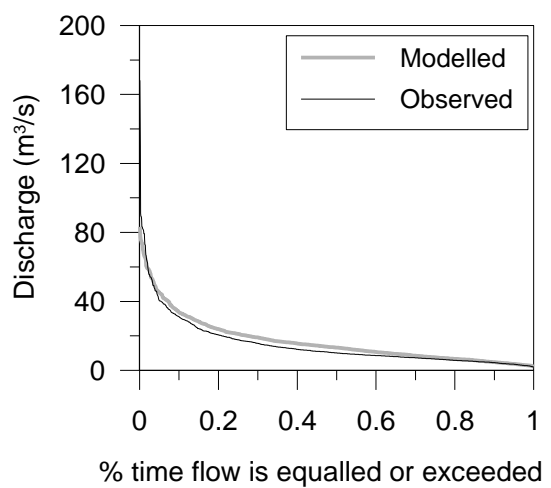

(a)

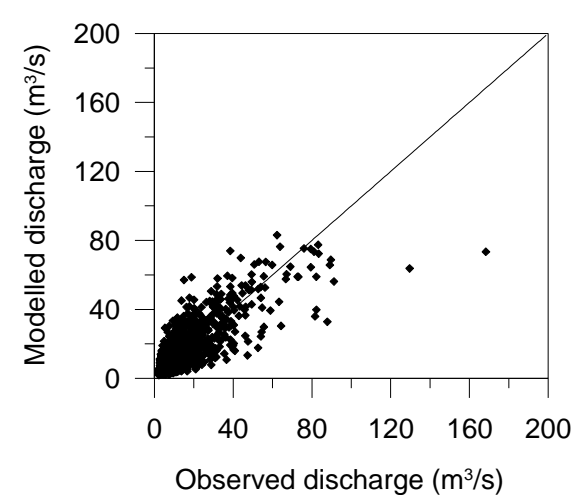

(b)

Figure 8. Daily flows of the Tomebamba basin: (a) flow duration curve; and (b) scatter plot.

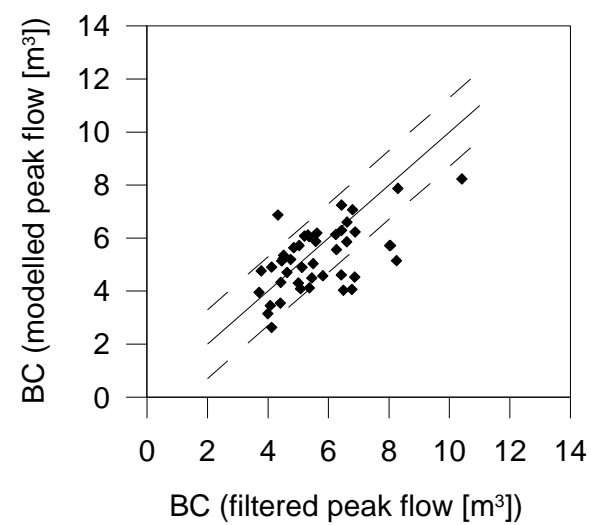

(a)

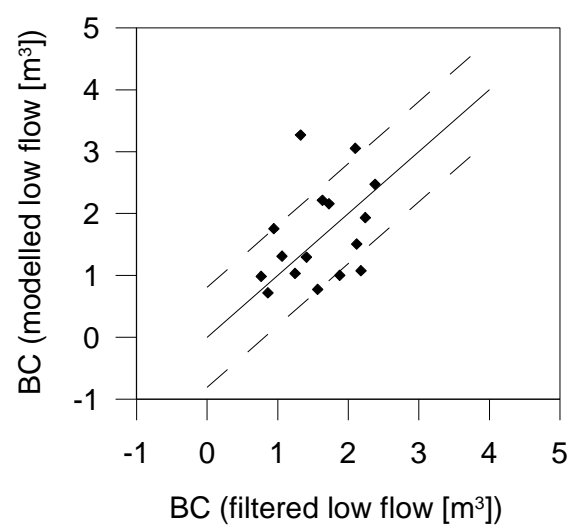

(b)

Figure 9. Evaluation of (a) quick flow events; and (b) slow flow events of the Tomebamba basin.

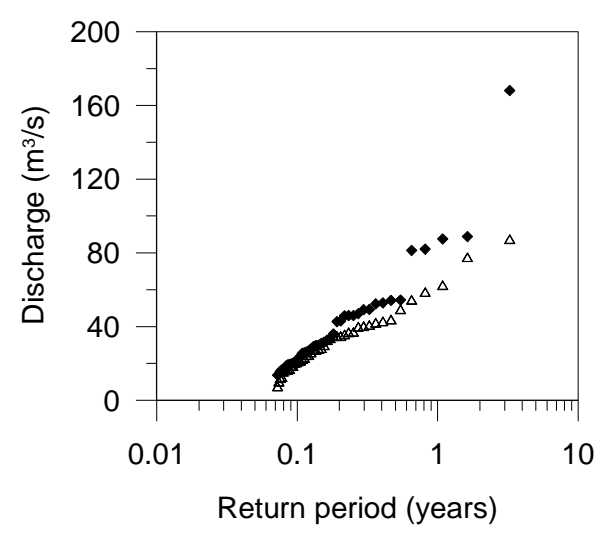

(a)

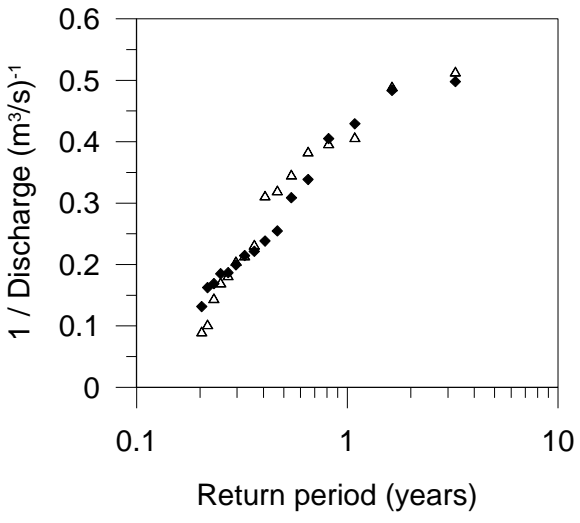

(b)

Figure 10. Evaluation of the simulation of extreme discharges of the Tomebamba basin: (a) high flows; and (b) low flows. Solid dots are observations, triangles are model results. 


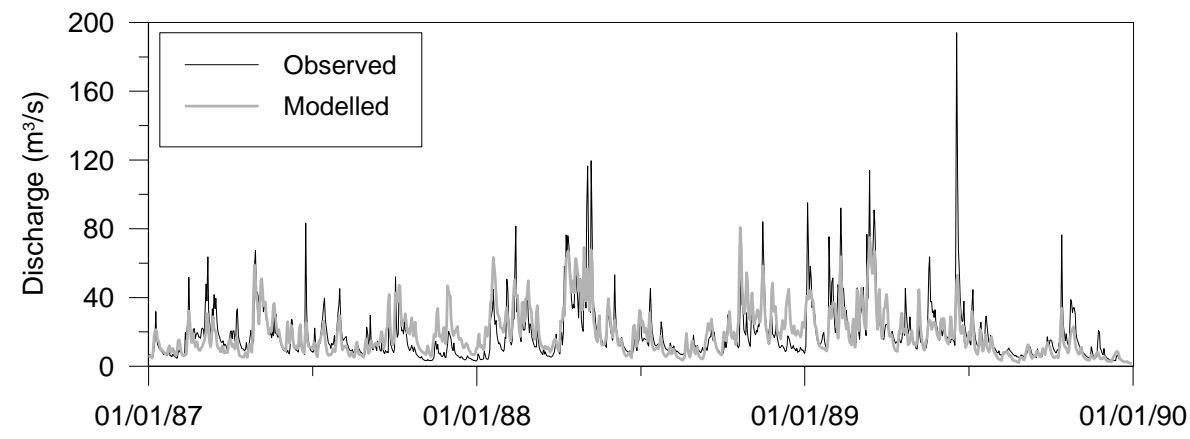

Figure 11. Timeseries of observed and simulated streamflow, using a 3 set-up model, during the validation period, with application to the Tomebamba basin.

Table 2. Model performance in calibration and validation (set-up 3)

\begin{tabular}{lcccc}
\hline \multirow{2}{*}{ Basin } & \multicolumn{2}{c}{ Calibration } & \multicolumn{2}{c}{ Validation } \\
\cline { 2 - 5 } & $\mathrm{EF}$ & $\begin{array}{c}\text { Water balance } \\
\text { error }(\%)\end{array}$ & $\mathrm{EF}$ & $\begin{array}{c}\text { Water balance } \\
\text { error }(\%)\end{array}$ \\
\hline Matadero & 0,63 & 1,5 & 0,51 & $-2,1$ \\
Tomebamba & 0,70 & 2,9 & 0,64 & $-0,5$ \\
\hline
\end{tabular}
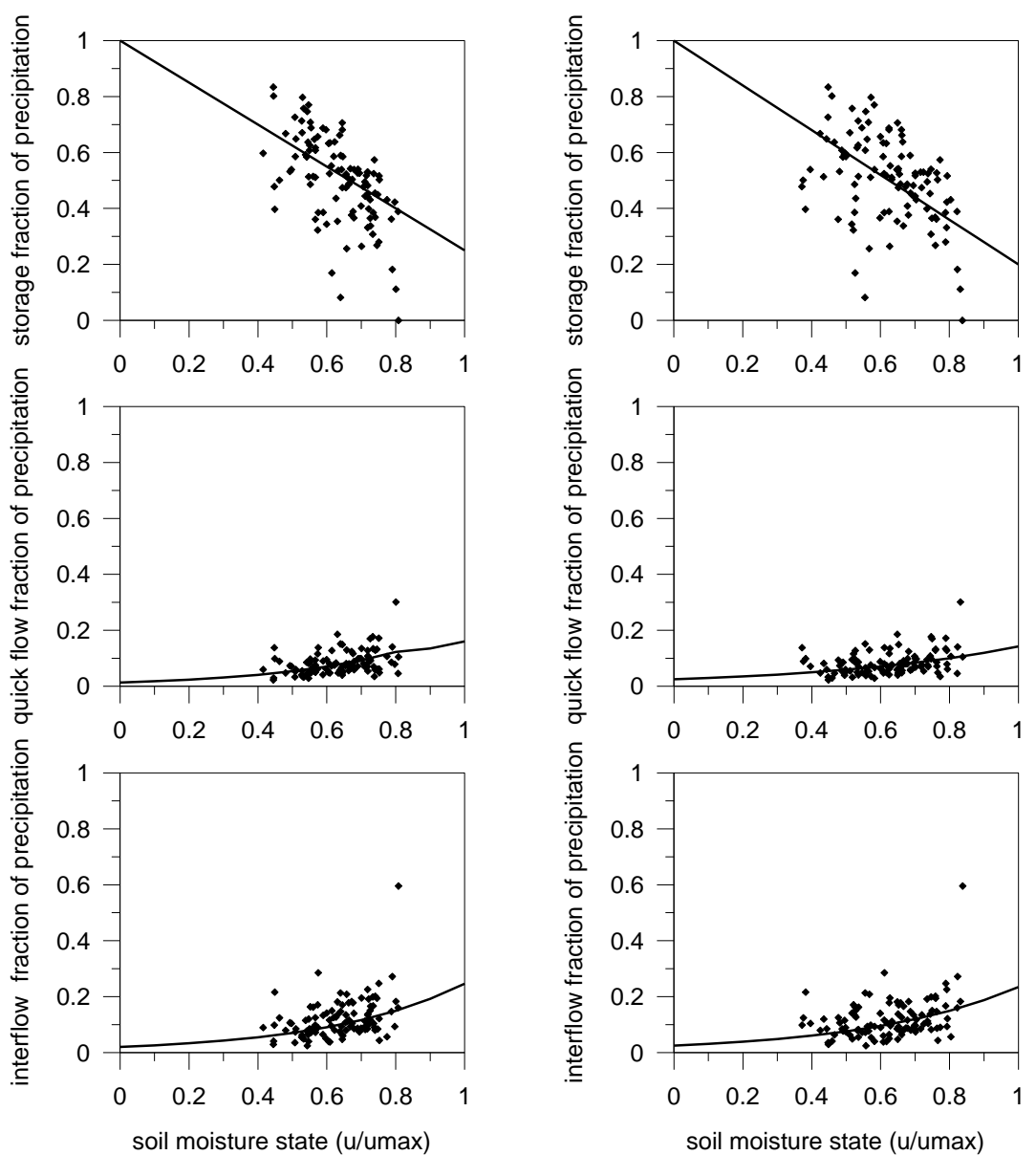

Figure 12. Effects of $u_{\max }$ on sub-module outputs with application to the Tomebamba basin: left high $u_{\max }(250 \mathrm{~mm})$; and right low $u_{\max }(125 \mathrm{~mm})$ value. 
A summary of model performance is presented in Table 2. In general, peak discharges were under-estimated by all analyzed model structures, and this for both study basins. Although this might be caused by an inappropriate model structure, it is more likely that it is caused by uncertain in the rainfall input, due to the sparse network of rain gauges. In fact, given the strong topographic gradient, rainfall is largely produced by condensation due to adiabatic cooling of orographically-lifted air masses (i.e., convective rainfall); therefore rain can be highly local and the likelihood of events being not registered is highly probable. A second issue is the low rainfall intensity used in the simulations since only daily data are available. Therefore, high-intensity rainfall events producing large runoff volumes could not be taken into account in the simulations.

It is correct to state that performance during the calibration and validation periods are acceptable for both the basins. It is interesting to notice that model performance does not depend on scale. This might suggests that performance depends more on the rainfall input and the physical characteristics of the basins, rather than on the scale. Bearing in mind the complexity of both study basins results are encouraging.

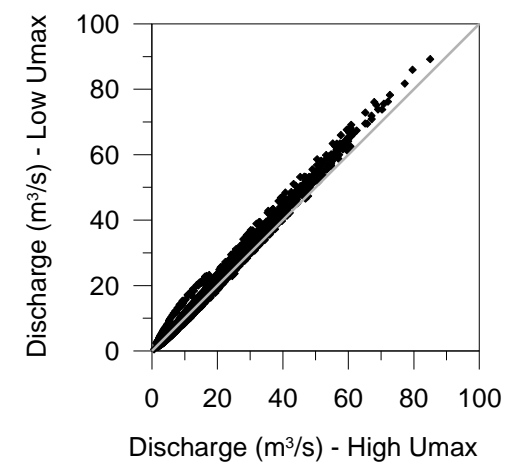

Figure 13. Scatter plot of simulated discharges for high (x-axis) and low (y-axis) $u_{\max }$ scenarios, with application to the Tomebamba basin.

\subsection{Sensitivity analysis for model parameters}

For the analysis of the effect of variations in soil water storage $\left(u_{\max }\right)$ on modeled streamflows two scenarios were applied: the first with a high $u_{\max }$ of $250 \mathrm{~mm}$ and the second with a low $u_{\max }$ of 120 $\mathrm{mm}$. The effect of $u_{\max }$ on the modules was evident as seen in Figure 12. The high $u_{\max }$ scenario produces a smaller variability in soil moisture state. This is likely due to the fact that the high $u_{\max }$ value reduces the basin to one big reservoir, requiring more water to reach saturation and from which water is slowly lost by evapotranspiration and baseflow. On the contrary the low um $u_{\max }$ scenario produces a larger variation in soil moisture state, which translates into easily identifiable sub-modules due the larger spread of observations in the $\mathrm{x}$-axis $\left(\mathrm{u} / u_{\max }\right)$. However, easily identifiable models do not necessarily turn into better-performance modules. For the Tomebamba the high $u_{\max }$ scenario shows a slightly better performance with water balance error of $2,8 \%$ (9\% for low $u_{\max }$ ) and EF of $0,69(0,66$ for low $u_{\max }$ ).

Figure 12 reveals that the chosen value for $u_{\max }$ can strongly affect all model parameters. Therefore, errors from an inaccurate $u_{\max }$ force other sub-modules parameters to compensate for it. This analysis gives a hint about the problems that an erroneous estimation of $u_{\max }$ can produce. The scatter plot of modeled discharges as seen in Figure 13 indicates that the low $u_{\max }$ scenario produces higher discharges being the result of the smaller storage capacity. As a measure to analyze the effects of model parameters on model performance confidence intervals (alpha level of 5\%) for every module were calculated and shown in Figure 14. As expected, the large scatter of SSM produces wider confidence intervals, while the QFM and IFM have very narrow intervals. QFM and IFM models built within the confidence intervals showed little variation in model parameters and therefore negligible effects on overall model performance (variation in $\mathrm{EF}$ was in the order of $\pm 0,02$ ). On the other hand, SSM model parameters can have a larger variation but their effect on module calibration (e.g., Figure 
$3 b$ ) is small. In fact, models similar to the best-fit model but with small variations in slope give similar performance mainly due to compensations between over- and under-estimated events. However, SSM models built outside the upper and lower intervals (while keeping QFM and IFM models unchanged) produce a strong reduction in model performance (EF for the Tomebamba basin dropped to 0,27). Additionally, the error introduced in the SSM model cascades down into the QFM and IFM models. However, even after recalibration of those models, efficiency only improved to 0,35 .
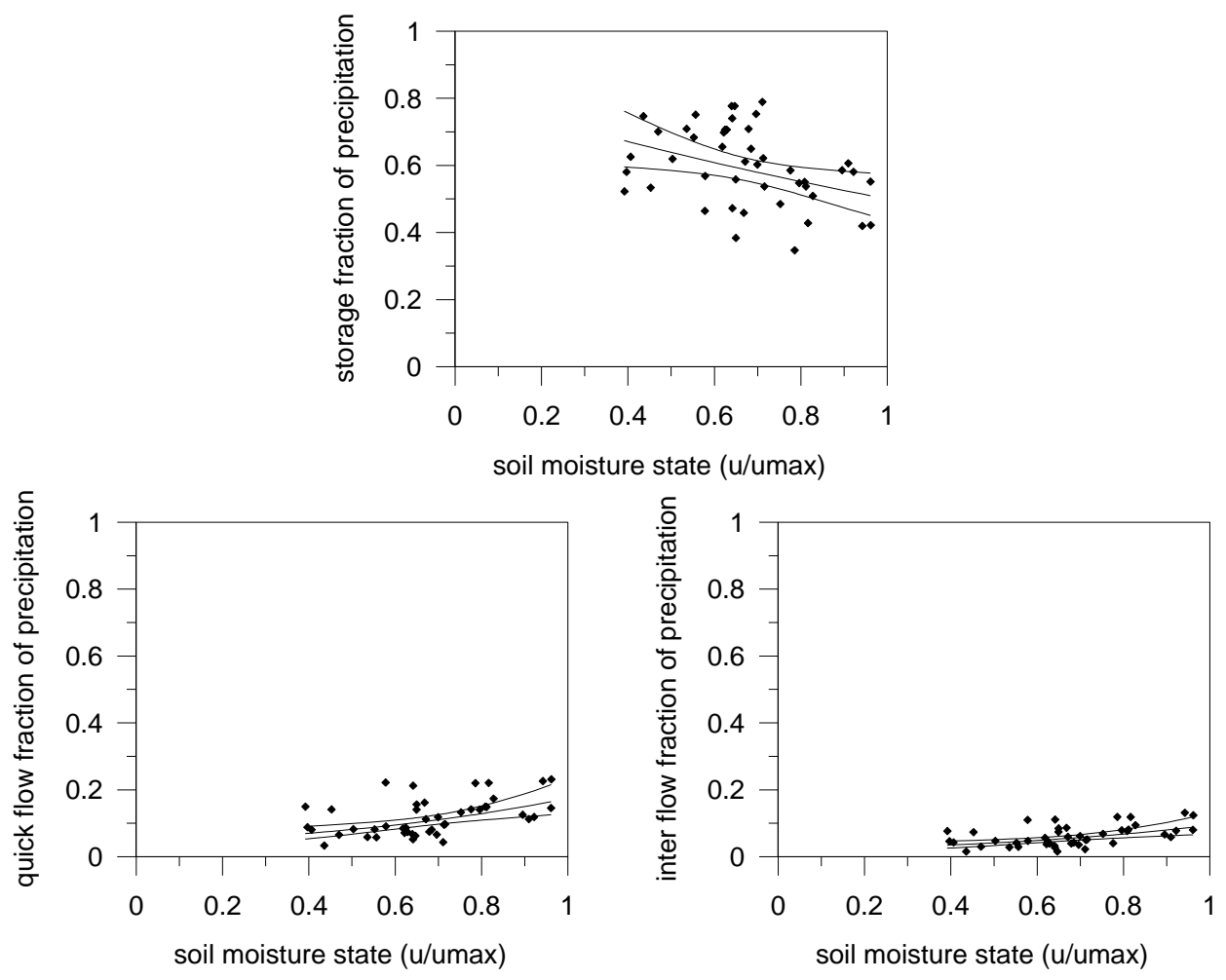

Figure 14. 95\% confidence intervals for the SSM, QFM and IFM modules, with application to the Tomebamba basin.

\section{CONCLUSIONS}

The objective of the study was to assess the capacity of a data-based hydrological model to simulate the runoff of mountain basins. The study was conducted with the VHM-approach (Willems, 2000) on two medium Andean river basins $\left(300-1260 \mathrm{Km}^{2}\right)$ of South Ecuador. The spatial scale of the basins was chosen as to fill the gap in knowledge of medium sized basins and given that at this scale most water management decisions are taken.

The VHM approach, a data-mining technique that follows the principles of the data-based mechanistic modeling, was used to identify the structure and parameter values of a modular, lumpedconceptual hydrological model. The model structure is determined as part of the calibration process. The VHM approach allows extracting useful information from the timeseries of observed discharge, and uses this information for constructing a robust, parsimonious hydrological model. The physicallybased information extracted from the discharge series are: (i) hydrological events, and (ii) the 3 components of the total flow: baseflow, interflow and quick flow. The hydrological model tied to the VHM approach uses a general conceptual model structure with storage elements representing the surface, unsaturated zone and groundwater storages. These storages are combined with linear reservoir models to describe the routing of the sub-flows. The basis of model implementation was the 
split-sample test and a step-wise approach for model calibration and validation. Model performance evaluation was carried out using multi-criteria objectives.

Six model structures were tested for the Tomebamba and Matadero basins, ranging from a basic 5-parameter model to a complex 15-parameter model. The simplest model structure (consisting of a module for soil storage and quick flow), according to the used multi-objective criteria, was able to simulate the water balance within acceptable limits and the Nash-Sutcliffe coefficient was regarded as good considering the conditions of input data limitation. Increasing the model complexity improved the EF coefficient only marginally. The use of the infiltration excess mechanism did not improve the simulations, likely due to the daily time step rainfall data. It was found that model performance does not depend on the spatial scale of the basin but is related to the quality of rainfall input and/or the variability in catchment properties. Considering the scale of application, the scarcity of rainfall data and spatial variability, results are satisfactory and encouraging.

A sensitivity analysis was conducted to analyze the effects of the maximum water storage capacity of the basin $\left(u_{\max }\right)$. This parameter cannot be mined from the data and therefore was derived by relating the terrain slope to soil depth. Low $u_{\max }$ values allowed an easier calibration of the different modules because they caused a larger spread on the soil moisture state (soils easily saturates and dries out). The easier calibration did not relate to model performance. Nevertheless, appropriate selection of $u_{\max }$ (e.g., via sensitivity analysis) is essential since this value affects all model parameters. Calibration plots of the quick flow and interflow modules provided a clear picture of the variability inherent in the observations. Models built within the confidence intervals of the observed events performed equally well.

Overall the study illustrates that the VHM approach: (i) strongly simplifies the process of model calibration and validation, (ii) reduces the risk of over-parameterization and model-associated uncertainty, and (iii) yields a robust operational model for the study region. It has been demonstrated that the information in the timeseries of discharge can be used to increase the knowledge on hydrological processes and the understanding of catchment functioning. For instance the analysis of the quick flow module indicates how likely/frequent a basin reacts to soil saturation.

\section{AKNOWLEDGEMENTS}

The first author acknowledges the doctoral grant received from the Research Council of the Katholieke Universiteit Leuven (K.U.Leuven), under the Bilateral Agreement between K.U.Leuven and Latin American Universities.

\section{REFERENCES}

Aizen, V., E. Aizen, G. Glarizin, H.A. Loaiciga, 2000. Simulation of daily runoff in Central Asian alpine watersheds. J. Hydrol., 238, 15-34.

Atkinson, S.E., R.A. Woods, M. Sivapalan, 2002. Climate and landscape control son water balance model complexity over changing timescales. Water Resour. Res., 38, 1314, doi: 10.1029/2002WR001487.

Babovic, V., 2005. Data mining in hydrology. Hydrol. Process., 19, 1511-1515.

Bacuilima, F., J. Bacuilima, W. Bermeo, 1999. Caracterización del clima por microcuencas en el austro ecuatoriano. Tesis de grado. Facultad de Ingeniería, Universidad de Cuenca, Cuenca, Ecuador.

Beven, K.J., A.M. Binley, 1992. The future of distributed models: model calibration and uncertainty prediction. Hydrol. Process., 6, 279-298. 
Box, G.E.P., D.R. Cox, 1964. An analysis of transformations. J. Roy. Stat. Soc., 211-243, Discussion 244-252.

Burlando, P., F. Pellicciotti, U. Strasser, 2002. Modelling mountainous water systems between learning and speculating. Nord. Hydrol., 33, 47-74.

Célleri, R., 2007. Rainfall variability and rainfall-runoff dynamics in the Paute river basin - Southern Ecuadorian Andes. PhD dissertation. Faculty of Engineering, Katholieke Universiteit Leuven. Leuven, Belgium.

Célleri, R., P. Willems, W. Buytaert, J. Feyen, 2007. Space-time rainfall variability in the Paute Basin, Ecuadorian Andes. Hydrol. Process., 21(24), 3316-3327.

Chapman, T., 1991. Comment on 'Evaluation of automated techniques for base flow and recession analyses' by Nathan RJ and McMahon TA. Water Resour. Res., 27, 1783-1784.

Croke, B.F.W., R.A. Letcher, A.J. Jakeman, 2006. Development of a distributed flow model for underpinning assessment of water allocation options in the Namoi River Basin, Australia. J. of Hydrol., 319, 51-71.

Eder, G., M. Fuchs, H.P. Nachtnebel, W. Loibl, 2005. Semi-distributed modelling of he monthly water balance in an alpine catchment. Hydrol. Process., 19, 2339-2360.

Frawley, W., G. Piatetsky-Shapiro, C. Matheus, 1992. Knowledge Discovery in Databases: An Overview. AI Magazine, 213-228.

Jakeman, A.J., I.G. Littlewood, P.G. Whitehead, 1990. Computation of the instantaneous unit hydrograph and identifiable component flows with application to two small upland catchments. J. Hydrol., 117, 275-300.

Klemes, V., 1983. Conceptualization and scale in hydrology. J. Hydrol., 65, 1-23.

Klemes, V., 1986. Operational testing of hydrological simulation models. Hydrolog. Sci. J., 31, 13-24.

Kokkonen, T.S., A.J. Jakeman, 2001. A comparison of metric and conceptual approaches in rainfallrunoff modeling and its implications. Water Resour. Res., 37, 2345-2352.

Lees, M.J., L.A. Camacho, P. Whitehead, 1998. Extension of the QUASAR river quality model to incorporate dead-zone mixing. Hydrol. Earth Syst. Sc., 2, 353-365.

Lees, M.J., 2000. Data-based mechanistic modelling and forecasting of hydrological systems. $J$. Hydroinformatics, 2, 15-34.

Limbrick, K.J., 2002. Estimating daily recharge to the Chalk aquifer of southern England - a simple methodology. Hydrol. Earth Syst. Sc., 6, 485-495.

Littlewood, I.G., B.F.W. Croke, A.J. Jakeman, M. Sivapalan, 2003. The role of 'top-down' modelling for Prediction in Ungaged Basins (PUB). Hydrol. Process., 17, 1673-1679.

Nash, J.E., I.V. Sutcliffe, 1970. River flow forecasting through conceptual models. J. Hydrol., 273, 282-290.

Post, D.A., A.J. Jakeman, 1996. Relationships between catchment attributes and hydrological response characteristics in small australian mountain ash catchments. Hydrol. Process., 10, $877-$ 892.

Refsgaard, J.C., J. Knudsen, 1996. Operational validation and intercomparison of different types of hydrological models. Water Resour. Res., 32, 2189-2202.

Schreider, S.Y., A.D. Jakeman, 2001.Streamflow modelling on a subdaily time step in the Upper Murray Basin. Math. Comput. Model., 33, 659-668.

Sefton, C.E.M., S.M. Howarth, 1998. Relationships between dynamic response characteristics and physical descriptors of catchments in England and Wales. J. Hydrol., 211, 1-16.

Singh, V.P., D.K. Frevert, 2002a. Mathematical models of large watershed hydrology. Water Resour. Publ., LLC.

Singh, V.P, D.K. Frevert, 2002b. Mathematical models of small watershed hydrology and applications. Water Resour. Publ., LLC. 
Tabios, G., J. Salas, 1985. Comparative analysis of techniques for spatial interpolation of precipitation. Water Resour. Bull., 21, 365-380

Tote, C., B. De Bièvre, 2005. Generación de mapas regionales de evapotranspiracion media mensual para el Austro Ecuatoriano. Informe interna, Programa para el Manejo del Agua y del Suelo, Universidad de Cuenca, Cuenca, Ecuador.

Willems, P., 2000. Probabilistic immission modelling of receiving surface waters. Ph.D thesis, Faculty of Engineering, Katholieke Universiteit Leuven, Leuven, Belgium.

Willems, P., 2004. WETSPRO: Water Engineering Time Series PROcessing tool, Methodology and User's Manual. Hydraulics Laboratory, Katholieke Universiteit Leuven, Leuven, Belgium.

Willems, P., 2005. Guidance document for calibration and verification of rainfall-runoff models. Internal report, Hydraulics Laboratory, Katholieke Universiteit Leuven, Leuven, Belgium, 25 pp.

Young, P., 1998. Data-based mechanistic modelling of environmental, ecological, economic and engineering systems. Environ. Modell. Softw., 13, 105-122.

Young, P., 2001. Data-based mechanistic modelling and validation of rainfall-flow processes. In: Anderson, B., P.D. Bates (Eds.). Model Validation: Perspectives in Hydrological Science. John Wiley and Sons, Ltd., 117-161.

Young, P., 2003. Top -down and data-based mechanistic modelling of rainfall-flow dynamics at the catchment scale. Hydrol. Process., 17, 2195-2217. 